\title{
Proletariado e Emancipação
}

Rafael Rossi ${ }^{1}$

\section{RESUMO}

A emancipação humana, cada vez mais, por uma série de motivos tem se tornado um conceito tratado com pouca rigorosidade e muita deturpação. Entendemos que este debate é tratado com profundidade pela ontologia marxiana, pois passa a discuti-la com base no próprio movimento histórico e social da realidade objetiva. Nesse aspecto, é preciso compreender a centralidade ontológica do trabalho e sua centralidade política, com intuito de contribuir para o resgate da perspectiva crítica e revolucionária do pensamento marxiano. Ao contrário do que muitos discursos disseminam o proletariado ainda é o sujeito revolucionário por excelência - porém não único - e isto deve ser debatido em amplos espaços perante todos aqueles comprometidos com a luta para além do capital e não dentro dos parâmetros de sua lógica incontrolável e estruturalmente desigual.

Palavras-chave: Capital. Emancipação Humana. Proletariado. Trabalho.

\section{Proletariat and Emancipation}

\section{ABSTRACT}

Human emancipation, increasingly, for a number of reasons has become a concept treated with little rigor and much misrepresentation. We believe that this debate is discussed in depth by the Marxian ontology, as it starts to discuss it based on own historical and social movement of objective reality. In this aspect, one must understand the ontological centrality of labor and its political centrality, in order to contribute to the rescue of the critical and revolutionary perspective of Marxian

1 Docente da Universidade Federal de Mato Grosso no Curso de Licenciatura em Educação do Campo e no Programa de Pós-Graduação de Ensino de Ciências. Mestre em Geografia pela UNESP/FCT de Presidente Prudente-SP. Doutor em Educação pela UNESP/FCT de Presidente Prudente-SP. E-mail: rafaelrossi6789@hotmail.com. 
thought. Contrary to what many speeches spread the proletariat is still the revolutionary subject par excellence - but not only - and this should be discussed in open spaces in front of all those committed to the fight beyond the capital and not within the parameters of his uncontrollable and structurally antagonic logic.

Keywords: Capital. Human Emancipation. Proletariat. Labor.

\section{Proletariado y emancipación}

\section{RESUMEN}

La emancipación humana, cada vez más, por una serie de razones se ha convertido en un concepto tratado con poco rigor y mucha distorsión. Creemos que este debate se discute en profundidad por la ontología marxista, ya que empieza a discutirla basado en el propio movimiento histórico y social de la realidad objetiva. En este respecto, hay que comprender la centralidad ontológica del trabajo y su centralidad política, con el fin de contribuir para el rescate de la perspectiva crítica y revolucionaria del pensamiento marxista. Contrariamente a lo que muchos discursos propagan el proletariado sigue siendo el sujeto revolucionario por excelencia - pero no sólo - y esto debe ser discutido en amplios espacios delante de todos aquellos comprometidos con la lucha más allá del capital y no dentro de los parámetros de su lógica incontrolable y estructuralmente desigual.

Palabras clave: Capital. Emancipación Humana. Proletariado. Trabajo.

\section{Introdução}

O presente texto constitui um instrumento para discutirmos a relação entre os proletários na atualidade e a necessidade histórica da luta pela emancipação humana, portanto, a luta para além do capital. É fundamental neste debate, resgatar o posicionamento crítico e radical da teoria marxiana a respeito da necessidade de destruição do Estado burguês, de superação do capital, do trabalho assalariado/abstrato, das classes sociais e da exploração do homem pelo homem. Se partirmos 
de uma perspectiva histórica e materialista, com foco no surgimento das classes sociais e na centralidade ontológica e política do trabalho, é possível compreender a razão do proletariado ser o sujeito revolucionário por excelência, porém não o único a efetivar o processo revolucionário.

Obviamente a gama de temas e reflexões que se entrelaçam é por demais complexa e ampla. Abordaremos, deste modo, em primeiro lugar, a centralidade política do proletariado na luta pela transição do capitalismo rumo ao socialismo. Já em um segundo momento é importante esclarecer as bases materiais da emancipação humana, ou seja, do comunismo, já que inúmeras foram - e ainda são - as deturpações que a obra de Marx sofreu.

Entendemos que as ideias "pilares" que estruturam a discussão sobre o proletariado e a emancipação humana são: 1) a centralidade ontológica e política do trabalho; 2 ) a compreensão do surgimento das classes sociais; 3 ) os limites objetivos da emancipação política; 4) o papel revolucionário do proletariado. Tais"pilares", de modo algum, simplificam ou resumem este debate, mas sim, contribuem para apreender a linha de argumentação crítica da perspectiva revolucionária marxiana.

Várias foram as teses e os discursos que, em alguns casos ainda hoje, abandonam do horizonte de suas análises a reflexão sobre o trabalho, tanto em sentido amplo, no que diz respeito à constituição do ser social e ao processo histórico do devir humano, quanto no que se refere à sua forma particular e histórica enquanto trabalho assalariado/ abstrato inerente ao capitalismo. Não se trata de resumir tudo mecanicamente ao trabalho. Ao contrário, é preciso explicitar o mais claramente possível o seu papel fundante no ser social. Sem a existência do intercâmbio orgânico do homem com a natureza para a produção dos meios de produção e de subsistência é impossível qualquer tipo de reprodução social. Aqui já vale um alerta: na reprodução social não se elimina a reprodução biológica, entretanto, aquela não se simplifica nesta. Na reprodução biológica ocorre sempre a reposição do mesmo e na reprodução social há sempre a criação do novo (LESSA, 2007; TONET, 2005).

Se perdermos de vista estas compreensões, muito pouco contribuiremos para a organização dos trabalhadores, em especial 
do proletariado, no desafio histórico de superar o capital rumo à emancipação humana.

\section{Centralidade Política Proletária}

Antes de entender propriamente a questão do proletariado enquanto sujeito revolucionário por excelência é preciso esboçar, mesmo que brevemente, os delineamentos gerais do trabalho enquanto categoria fundante do "mundo dos homens". Com relação à centralidade ontológica (ou seja, o fato de estar presente em todas as formações sociais, inclusive, hoje, no capitalismo) do trabalho, parte-se do pressuposto de que o único animal que trabalha são os seres humanos e isso, por sua vez, dá início a um processo complexo de desenvolvimento da reprodução social em que outros complexos (educação, arte, filosofia, ciência etc.) irão, também, jogar um papel importantíssimo. Isso pode ser apreendido quando os autores afirmam que: "As abelhas produzem mel e permanecem sempre as mesmas, as formigas vivem sempre da mesma maneira. Os seres humanos, contudo, ao retirarem da natureza o que precisam, também se transformam" (TONET; LESSA, 2012, p. 9). Este é um argumento de fundamental importância, pois é possível, "logo de cara", excluir todo imbróglio academicista que, costumeiramente, postula o "fim do trabalho" ou o fato de que vivemos em uma "sociedade do conhecimento e da informação". O trabalho - assim como esclarece Marx - é uma necessidade "eterna" dos seres humanos, ou, para utilizar uma expressão de Lukács (2012), o trabalho pode ser considerado o "fenômeno originário", o "modelo do ser social". O trabalho assalariado/ abstrato é outra história, pois esta é a forma histórica do trabalho no capitalismo. Não é por mero acaso que:

Qualquer forma de sociedade seria inviável se ela não dispusesse da natureza como fonte de meios de subsistência e meios de produção. Toda sociedade tem sua existência hipotecada à existência da natureza - o que varia historicamente é a modalidade de organização dos homens para transformarem natureza: variam, ao longo da história, os objetos produzidos a partir dos elementos naturais, bem como os meios empregados nessa transforma- 
ção; mas permanece o fato de que a reprodução da sociedade depende da existência da natureza. Isto continua sendo válido mesmo para a sociedade capitalista mais avançada no preciso sentido de que sem a transformação da natureza o capital produzido ou valorizado pela exploração do trabalho abstrato não poderia sequer existir. $O$ que a sociedade burguesa tem de "novo" frente às formações sociais pré-capitalistas não inclui o desaparecimento do trabalho, mas sim sua subsunção ao capital. Esta subsunção, todavia, também por ser o fundamento das alienações peculiares à sociedade burguesa, não implica nem na identidade entre trabalho e trabalho abstrato, nem no desaparecimento do primeiro. (LESSA, 2007, p. 132, grifos nossos).

Esta primeira distinção entre a reprodução biológica e a reprodução social é da mais extrema importância. O trabalho "chama à vida" - para usar uma expressão de Lukács - outros complexos sociais (educação, filosofia, arte etc.) que possuem uma função social diferente no processo de reprodução social. Isto, logo de saída, já nos possibilita afastar posicionamentos que pretensamente afirmam a simplificação mecânica do ser social ao trabalho. Esta categoria, como o próprio Lukács (2012) nos explica, só pode existir no interior de uma totalidade social, consubstanciando um "complexo de complexos". Este raciocínio também permite compreender como os atos de trabalho "sempre remetem para além de si mesmos" (LUKÁCS, 2012), ou seja: o trabalho implica num resultado maior do que aquele inicialmente projetado. Ao fazer uma lança, por exemplo, um homem da sociedade primitiva desenvolvia uma série de habilidades e conhecimentos passíveis também de serem utilizados em várias outras situações e contextos. Por isso que:

Para irmos direto ao núcleo do problema, enquanto a história da esfera da vida é o desenvolvimento das espécies biológicas, a história dos homens é o desenvolvimento de formações sociais sem qualquer alteração significativa da espécie biológica Homo sapiens. Enquanto, na natureza, a mera reprodução biológica determina o desenvolvimento dos seres vivos, a reprodução das sociedades é um processo que inclui condições que sequer existem na natureza como lutas de classe, ideologia, trabalho etc. Isto significa que se trata de esferas de ser ontolo- 
gicamente diferentes e não apenas de diferenças de graus no interior da "natureza". Realmente, marcando a distinção entre a natureza inorgânica e a orgânica, há a vida - a capacidade de reproduzir a si mesmo rigorosamente desconhecida do inorgânico que apenas opera reações químicas ou processos físicos. $\mathrm{E}$ diferenciado a natureza (inorgânica e orgânica) da sociedade, há uma constelação de complexos (linguagem, trabalho, relações sociais, arte, religião, etc.) que consubstanciam esta última como um outro tipo de ser, que não só é extremamente mais complexo que o ser natural (inorgânico e orgânico), mas que, sobretudo, não pode ser derivado da natureza. (LESSA, 2007, p. 133, grifos nossos).

Como se observa a história da reprodução social é distinta da história da reprodução biológica, ainda que aquela necessite desta para existir. Assim como os seres humanos criaram as relações sociais eles também podem transformá-las. Já na vida natural, não podemos, por exemplo, cancelar a lei da gravidade. Os limites naturais "condicionam externamente a sociedade", ou seja, "podem favorecer ou prejudicar alguns desenvolvimentos sociais", todavia, "jamais determinam os processos sociais". Em razão disto que "as relações entre os homens não derivam da natureza, mas das características históricas da sociedade", por exemplo: "a instituição da escravatura ou da servidão nada tem a ver com as condições do relevo ou do clima" (LESSA, 2007, p. 134). Deste modo:

O trabalho é, pois, a categoria fundante do mundo dos homens porque, em primeiro lugar, atende à necessidade primeira de toda sociabilidade: a produção dos meios de produção e de subsistência sem os quais nenhuma vida social poderia existir. Em segundo lugar, porque o faz de tal modo que já apresenta, desde o seu primeiro momento, aquela que será a determinação ontológica decisiva do ser social, qual seja, a de que, ao transformar o mundo natural, os seres humanos também transformam a sua própria natureza, o que resulta na criação incessante de novas possibilidades e necessidades históricas, tanto sociais como individuais, tanto objetivas quanto subjetivas. (LESSA, 2007, p. 142, grifos nossos). 
Uma vez que entendemos a centralidade ontológica do trabalho na reprodução social, podemos avançar para a discussão a respeito do surgimento das sociedades de classes. A partir do trabalho excedente propiciado pela Revolução Neolítica (aproximadamente 12 mil anos atrás), para que as forças produtivas continuassem se desenvolvendo se tornou "lucrativo" - digamos assim - um grupo humano explorar outro grupo de seres humanos e viver com o fruto do trabalho alheio. Este processo histórico deu origem ao surgimento das classes sociais, baseadas no aparecimento da propriedade privada, isto é, no fato de uma classe se apropriar privadamente do fruto do trabalho de outra classe. Podemos, agora, observar a centralidade política do trabalho, pois "o modo como se extraem da natureza os meios de produção ou de subsistência, a forma como se trabalha, determina a existência e a natureza das classes sociais" (TONET; LESSA, 2012, p.17), inclusive, se existirão ou não classes sociais. Nas sociedades primitivas, fundadas pelo trabalho de coleta, a vida social exigia que coletivamente as pessoas dividissem os produtos do trabalho de modo igualitário. Nas sociedades de classes (escravismo, modo de produção asiático, feudalismo e capitalismo) fundadas no trabalho alienado e na propriedade privada, é uma impossibilidade objetiva a divisão igualitária dos frutos do trabalho. Apenas numa sociedade de emancipação humana, ou seja, no comunismo, será possível os homens se desenvolverem plenamente e ter acesso a todos os bens construídos pelos próprios homens, pois não mais o trabalho alienado e a propriedade privada fundarão esta nova forma de sociabilidade.

Em outras palavras: a centralidade política do trabalho não pode ser confundida com centralidade da política. A centralidade política do trabalho trata de apreender a forma determinada do trabalho em cada modo de produção, fundando uma totalidade social específica com limites e possibilidades objetivas e orientando - em linhas gerais - a dinâmica de cada complexo social. Um exemplo real: é impossível a existência da cidadania moderna no feudalismo. A base da cidadania moderna está em todos serem livres (trabalhadores são livres para vender sua força de trabalho, a quem estiver disposto a comprá-la, e os capitalistas, por sua vez, são livres para comprar a força de trabalho 
daqueles trabalhadores que julgarem mais aptos), iguais (juridicamente o capitalista é igual ao trabalhador, todavia, se trata de uma igualdade formal fundada sobre uma base de desigualdade real) e proprietários (os trabalhadores são proprietários de sua força de trabalho e os capitalistas do capital). Estas três características indispensáveis para a cidadania moderna é uma conquista da revolução burguesa que derrubou o poder político do Estado absolutista típico do feudalismo e, também, superou o trabalho servil com suas limitações e barreiras. Em razão disto que os autores afirmam que a passagem ao modo de produção capitalista implica numa nova forma de propriedade privada que está "desvinculada de uma relação necessária com qualquer porção da natureza". Isto é:"esta nova propriedade privada é o capital, que se expressa imediatamente no dinheiro" (TONET; LESSA, 2012, p. 26). Todavia, diferentemente do modo de produção escravista e feudal em que a propriedade privada era a do senhor de escravos e do senhor feudal, respectivamente, no capitalismo a "forma social desta riqueza é o capital" (TONET; LESSA, 2012, p. 28).

O trabalho assalariado que funda o capitalismo promove uma ampliação da capacidade de abstrair mais-valia pelo capital, tanto daquelas atividades que estão transformando a natureza para a produção dos meios de produção e de subsistência, quanto para aquelas atividades que estão baseadas nas relações dos homens entre si. Em face disto que também consideramos o conceito marxiano de trabalho abstrato. Este trabalho abstrato no modo de produção capitalista é mais amplo e mais estreito, ao mesmo tempo. É mais amplo "porque inclui outras práxis que não apenas o intercâmbio orgânico com a natureza" e, é também, mais estreito "porque só produz mais-valia" (LESSA, 2005, p. 111). Este fato, entretanto, não quer dizer que todos os assalariados desempenhem a mesma função no processo de reprodução social. É isto que permite compreender a posição do proletariado no processo produtivo:

A esta primeira diferença entre a função social do proletariado (produz mais-valia ao converter a natureza no "conteúdo material da riqueza social") e a dos trabalhadores produtivos (que produzem mais-valia sem necessariamente produzirem o "conteúdo material da riqueza social") - e entre 
estes últimos e os assalariados (nem todos os assalariados produzem mais-valia), há também os trabalhadores improdutivos como os funcionários públicos, os professores nas escolas públicas e os "superintendentes", se agrega uma outra: A distinção entre as práxis do professor e a do proletário [...] No caso do proletário, temos o "processo entre o homem e natureza"; no caso do professor, a relação é exclusivamente entre seres humanos. Isto não significa que a práxis do professor não tenha que recorrer a instrumentos que são natureza transformada, como o giz e a sala de aula. Mas a função social do professor não é a produção destes produtos, mas sim atuar na transformação da substância da personalidade de seus alunos pelo ensino de novos conhecimentos, costumes, valores, etc. O que, também, não significa dizer que o intercâmbio com a natureza não seja social, mas apenas que o proletário e o professor objetivam atos teleológicos orientados a finalidades substancialmente diversas: 0 primeiro transforma a natureza, o segundo, a substância social da personalidade de seus alunos. (LESSA, 2007, p. 173 , grifos nossos).

Estas considerações de Lessa (2007) são fundamentais para nosso debate. $\mathrm{O}$ trabalho abstrato no âmbito do capitalismo congrega uma série de atividades. Dentre todos os assalariados, temos aqueles que produzem mais-valia (trabalhadores produtivos, por exemplo: professores de escolas particulares e operários de uma usina de celulose) e os que não produzem mais-valia (trabalhadores improdutivos, por exemplo: funcionários públicos). Dentre os trabalhadores produtivos, temos aqueles que transformam a natureza e produzem o capital com o seu trabalho (proletários, por exemplo: operários de uma fábrica de aviões) e aqueles que não estão transformando a natureza, mas sim, operando na relação dos homens entre si (professores em instituições privadas, por exemplo). Dessa forma, o proletariado é a única classe da "sociedade capitalista que produz o 'conteúdo material da riqueza', que 'produz' o 'capital', pois é ela a única classe que exerce a função social de converter a natureza" nos meios de produção e de subsistência. $\mathrm{O}$ proletariado é a única classe "cujo trabalho produtivo 'produz' não apenas mais-valia, mas também 'capital', que produz originalmente toda a riqueza social, o'capital social total'"'(LESSA, 2007, p. 179). 
É perceptível, nessa perspectiva, que a distinção entre proletários e os demais assalariados não se baseia puramente em aspectos especulativos idealistas, mas sim pelo local que os indivíduos ocupam na estrutura produtiva. Entre os proletários e os outros assalariados há uma diferença qualitativa que se origina no "solo social objetivo": os primeiros produzem o "conteúdo material da riqueza" e os segundos vivem do "conteúdo material da riqueza" que fora produzido pelo proletariado. É isto que "faz do proletariado a classe revolucionária por excelência", pois é a "única classe que, na acepção mais radical da expressão, nada tem a perder, e tudo a ganhar, com o fim da propriedade privada" (LESSA, 2007, p. 201).

É neste sentido que podemos entender o significado histórico das revoluções burguesas e, com efeito, a distinção qualitativa da revolução proletária. Afirmamos anteriormente que toda sociedade é fundada com base num determinado tipo de trabalho. No capitalismo é o trabalho assalariado/abstrato que funda a totalidade social e orienta o direcionamento dos demais complexos. Se voltarmos nossa atenção para a distinção das atividades produtivas, veremos que, dentre todos os assalariados, apenas o proletário produz o capital com seu trabalho, pois apenas ele transforma a natureza para a produção de valores de uso e, por meio de seu trabalho, é gerada a mais-valia que é apropriada pelos capitalistas. Aí reside a importância em compreender a teoria revolucionária de Marx, por exemplo, e não confundir trabalho produtivo, improdutivo, assalariado, abstrato e proletário. Esta é uma discussão de extrema relevância e implicância teórica e política.

Deste modo, a superação radical de todas as formas de desigualdade social e de exploração passa, hoje, invariavelmente, pela necessidade da revolução proletária. Este processo será "a abertura da transição ao modo de produção comunista". Neste sentido, uma nova forma de trabalho fundará a sociabilidade comunista: o trabalho associado com a "livre organização dos trabalhadores associados". Este entendimento não possui nada de "messianismo" com relação ao papel do proletariado. Apenas ele produz e valoriza o capital e, em decorrência desta sua posição no processo produtivo, apenas ele é o sujeito revolucionário por excelência. Isto, todavia, não quer dizer que 
ele será o único a desempenhar a revolução, mas sim que a sua liderança é imprescindível. Por isso que "o proletariado apenas pode emancipar da exploração se for capaz de se emancipar do domínio do capital" e para isso é "imprescindível uma radical subversão do trabalho" (TONET; LESSA, 2012, p. 60).

Revolução proletária, dessa forma, precisa ser entendida enquanto destruição do Estado burguês e "alteração essencial do trabalho", articulando um "momento político" e um "momento social". No caso do trabalho associado, há o "controle livre, consciente, coletivo e universal dos produtores sobre o processo de produção e distribuição da riqueza" (TONET; LESSA, 2012, p. 58). Por isso mesmo é preciso ter clareza de que sem a "destruição revolucionária do sistema do capital" não será possível superar todas as formas de exploração e desigualdade. O capitalismo não poderá ter uma "morte natural" como os autores nos explicam e, inclusive, "sem o proletariado como sujeito, nenhuma revolução terá a potência para superar o capital" (TONET; LESSA, 2012, p. 105). Com efeito, todos estes entendimentos são decisivos, pois concordamos com os autores ao afirmarem que: "só explicitando, o mais claramente possível, nossos pressupostos tornamos possível ao leitor a apropriação crítica do que escrevemos" (TONET; LESSA, 2012, p. 07). E essa é uma tarefa do proletariado e de todos os trabalhadores que deve ser orientada pela emancipação humana.

\section{Emancipação Humana: para onde isso aponta?}

Uma vez que compreendemos a centralidade ontológica e política do trabalho, o surgimento das classes sociais e as bases da cidadania moderna fundada a partir do trabalho assalariado, podemos então, avançar para a apreensão crítica da emancipação política do capital. Como se sabe, Marx diferenciava os termos "emancipação política" e "emancipação humana" e, portanto, não são sinônimos. De modo geral, a emancipação política é "precisamente a substituição do Estado pelo mercado na regulamentação do funcionamento da economia". Assim, a sociedade burguesa não "é o reino da liberdade humana, mas o reino da liberdade do capital". A emancipação humana 
é a humanidade emancipada do capital, da "propriedade privada e de tudo que a acompanha" (TONET; LESSA, 2012, p. 47).

A emancipação política é a base da origem da democracia e da cidadania. Perante o Estado, capitalistas e trabalhadores são igualmente cidadãos. Por isso, aquelas três características básicas que mencionamos anteriormente com relação à cidadania moderna (todos serem livres, iguais e proprietários). Todavia, "na medida em que o Estado ignora as reais desigualdades entre os indivíduos, ele na verdade permite ao capitalista a maior liberdade para explorar os trabalhadores e proletários" (TONET; LESSA, 2012, p. 48). Temos, dessa forma, que:

\begin{abstract}
A democracia é precisamente isso: a forma ideal de organização política que possibilita ao capital exercer seu domínio da maneira mais desimpedida. Ela é incapaz de superar a desigualdade social porque sequer pode considerar as diferenças geradas por ela. Por isso, cabe ao mercado (ao capital) determinar o que será produzido, como será produzido e com quem ficará a riqueza produzida. (TONET; LESSA, 2012, p. 49-50, grifos nossos).
\end{abstract}

Este debate é fulcral na radicalidade revolucionária do debate desenvolvido por Tonet e Lessa. Nos mais variados "modismos de esquina" é comum a defesa intransigente, superficial e messiânica da democracia e da cidadania sem a apreensão de sua origem, de sua gênese e de sua função social no processo de reprodução desta forma de sociabilidade burguesa. Tonet e Lessa (2012), entretanto, fazem um "mergulho" muito mais profundo, de modo claro e sucinto. Tanto a democracia quanto a cidadania são incapazes de permitir o pleno desenvolvimento das potencialidades e capacidades humanas em um caráter universal. Ambas são formas políticas necessárias para a manutenção deste sistema burguês. Isso, mais uma vez, em decorrência da democracia estar circunscrita à emancipação política do capital.

[...] a emancipação política implica a dissolução da velha sociedade feudal, na qual não havia separação entre sociedade civil e Estado e na qual os entes singulares estavam irrevogavelmente subsumidos às ordens sociais ou às corporações de ofício. Deste modo, a emancipação política significou tanto 
a separação entre sociedade civil e Estado - sem que isto implicasse nenhuma dissolução do vínculo ontológico entre eles, mas apenas uma nova configuração - quanto à cisão da sociedade em duas esperas - privada e pública - sendo a segunda, a expressão da primeira. O Estado, portanto, não é apenas um instrumento de defesa dos interesses particulares da burguesia, mas também uma expressão invertida da desigualdade social de raiz. Invertida, porque o interesse particular, que reina soberano na sociedade civil, apresenta-se, na sociedade política, sob a forma de interesse geral. (TONET, 2005, p. 72, grifos nossos).

O Estado, continua no capitalismo a proteger a propriedade privada, todavia, ele, agora, também serve de "instrumento da defesa dos interesses particulares da burguesia" e, também, é uma "expressão invertida", pois apresenta a "igualdade formal" fundada sobre uma base de desigualdade real. Por isso mesmo que a "emancipação política, por ser essencialmente limitada, não pode ser posta como objetivo último da humanidade, como patamar mais propício para a construção de uma sociedade livre, igual e fraterna" (TONET, 2005, p. 78).

A categoria fundante do ser social e, portanto, de toda forma de sociabilidade é o trabalho e não a política. Em outras palavras: "a questão, para Marx, posta da perspectiva do trabalho, cifra-se precisamente pela ruptura do anel vicioso", ou seja, é preciso superar as limitações da política pelo poder das bases materiais efetivadas no intercâmbio orgânico do homem - sociedade - com a natureza. A emancipação humana leva em conta a "reunificação e reintegração de posse, social e individual, de uma força que estivera alienada" e isto se relaciona à "força de se produzir e reproduzir, na individuação e na livre associação comunitária, pela única forma que o homem conhece e da qual é capaz - a sua própria atividade" (CHASIN, 2012a, p. 25). Com efeito, ela aponta para a "auto-organização e desenvolvimento universal do trabalho", enquanto "atividade livre e essencial da própria individuação" (CHASIN, 2012a, p. 25). Em síntese, temos que:

1 - a emancipação política ou parcial é um avanço irrecusável, mas não é o ponto de chegada da construção da liberdade; resume-se à liberdade 
possível na (des)ordem humanossocietária do capital; sua realidade é o homem fragmentado, impotente como cidadão e emasculado como ser humano, diluído em abstração na primeira metade e reduzido à naturalidade na segunda;

2 - a emancipação universal ou humana não é mais da lógica das liberdades restritas, condicionadas pela malha de determinações externas ao homem, mesmo que por ele próprio construídas, mas a construção da mundaneidade humana a partir da lógica inerente ao humano, ou seja, de ser social, cuja natureza própria ou "segredo ontológico" é a autoconstituição;

3 - a emancipação humana ou revolução social do homem compreende:

A - a reintegração pelo homem real da figura do cidadão, ou seja, a reincorporação e o desenvolvimento da capacidade de ser racional e justo, mera aspiração piedosa na esfera da política, tornando a ética possível, porque imanente ao ser que se autoedifica, de modo que ele não mais aliene de si força humanossocietária, degenerada e transfigurada em força política, assim tornando impossível, além de inútil, o aparecimento desta, o que derruba as barreiras atuais para a retomada da autoconstrução do homem;

$B$ - o reconhecimento e a organização - racional e humanamente orientada - das próprias forças individuais como forças sociais, de tal sorte que a individualidade, isolada e confundida com o ser mudo da natureza, quebre a finitude do ser orgânico e se alce à universalidade de seu gênero.

A emancipação humana é, portanto, para Marx, a revolução permanente do homem, e enquanto tal infinita.

Por ela, sim, vale a pena lutar, ao menos para superar as embrutecedoras ilusões políticas, hoje definitivamente esgotadas, tanto quanto a própria função da politicidade já mostra hoje sintomas agudos de inutilidade histórica. (CHASIN, 2012b, p.53-54, grifos nossos).

Chasin (2012b), na esteira de Marx, reconhece os avanços da emancipação política do capital frente aos modos de produção anteriores. Este é um caráter histórico inegável. Certamente é melhor ser trabalhador assalariado e cidadão do que servo ou escravo. Contudo, ao mesmo tempo, é de suma relevância compreender que ela não implica 
a plena realização dos indivíduos, isto é, de suas forças individuais enquanto forças sociais, pois a emancipação política está dentro do escopo de abrangência da lógica irreformável e irrefreável do próprio capital. A emancipação humana ou universal, ao contrário, implica a superação do capital, de suas limitações políticas manifestas nas bases da democracia e da cidadania. Por isso não basta, por exemplo, lutar pela manutenção da emancipação política para garantir uma forma de sociabilidade superior à capitalista. Este é um entendimento que perpassa a concepção de propriedade privada para além da sua expressão jurídico-política:

Ora, sem dúvida, a supressão da propriedade privada é um requisito absolutamente fundamental para a emancipação humana. Mas é preciso ter claro que a essência da propriedade privada não é a posse, garantia jurídica e politicamente, dos meios de produção. Esta é apenas a expressão de algo mais profundo, ou seja, de determinadas relações que os homens estabelecem entre si no trabalho. Estas relações implicam a apropriação, por parte de alguns, não apenas do produto do trabalho, mas principalmente da força de trabalho - e, em certas formas de trabalho, até da própria pessoa do trabalhador (escravidão) - o que resulta numa relação indissolúvel de exploração e de dominação. De modo que a supressão político-jurídica da propriedade privada, a estatização dos meios de produção e até o controle imediato da produção pelos trabalhadores não são, de modo nenhum, sinônimo de apropriação social. Repitamos: a apropriação social é o controle, consciente e coletivo dos trabalhadores - todos os homens - sobre a totalidade do processo produtivo. (TONET, 2005, p. 89-90, grifos nossos).

A elaboração de Tonet (2005) é decisiva nesta questão. A emancipação humana que deve orientar a luta do proletariado implica na concepção crítica mais radical possível de propriedade privada, apontando para o fato da "apropriação, por parte de alguns, não apenas do produto do trabalho, mas principalmente da força de trabalho". Justamente é isto que ocorre no âmbito do trabalho assalariado/abstrato que funda a sociabilidade burguesa. A apropriação não é feita pelos 
próprios produtores, mas pelo capital, que comanda todo o processo produtivo, reduzindo a essência humana apenas à lógica mercantil. Já na emancipação humana
[...] as coisas se passam de modo inteiramente dife- rente. $\mathbf{O}$ matrizamento desta forma de sociabilida- de pelo trabalho associado põe a base, sem a qual isto seria impossível, para que o ser social se torne uma comunidade efetiva, real, ou seja, uma forma em que as relações entre os indivíduos e o gênero e dos próprios indivíduos entre si sejam de união, de mútua complementaridade, de mútuo enriquecimento. (TO- NET, 2005, p. 122, grifos nossos).

Se toda sociedade é fundada num determinado tipo de trabalho que, junto àquela totalidade social, exerce o momento predominante na orientação de cada complexo social (educação, filosofia, arte, ciência etc) é imprescindível que outra forma de trabalho seja a categoria fundante da emancipação humana/comunismo. Esta forma de trabalho, que Marx analisou em vários textos e que é discutida em profundidade por Tonet, se chama trabalho associado. Este é um argumento extremamente racional para o debate da emancipação humana, com intuito de provar sua viabilidade real a partir do patamar de abundância gerado pelo desenvolvimento das forças produtivas no capitalismo que, em face da própria lógica de funcionamento deste modo de produção, se converte na miséria da maior parte dos trabalhadores. Já com o trabalho associado isto não acontece. Deste modo:

[...] a emancipação humana nem é um resultado
inevitável do processo histórico, nem uma utopia
impossível. Do mesmo modo, nada tem a ver com
uma fantasiosa sociedade paradisíaca, nem é ape-
nas um horizonte indefinível, jamais concretizável.
Também nada tem a ver com uma forma totalitária de
sociabilidade e com a supressão das diferenças e da
individualidade. Em seus traços gerais, únicos que po-
dem ser hoje claramente identificados, é uma forma
de sociabilidade que, fundada na materialidade
do trabalho associado, permite aos homens serem
os verdadeiros protagonistas do seu destino. O
que, obviamente, não os isenta das limitações ineren-
tes ao mundo humano. E, mais do que qualquer ou- 
tra forma de sociabilidade, exatamente por causa do patamar em que a humanidade se encontra, é uma alternativa possível - seguramente a melhor para a humanidade - mas, apenas uma possibilidade cuja efetivação depende dos próprios homens. (TONET, 2005, p. 125-126, grifos nossos).

Portanto, não é possível - numa análise materialista e histórica - considerar a emancipação humana como uma "sociedade paradisíaca e perfeita". Ela é uma forma superior de sociabilidade fundada no trabalho associado em que os próprios produtores terão o controle livre, consciente, coletivo e universal do processo produtivo, determinando as formas, os meios, o tempo e tudo relacionado à atividade vital que envolve os meios de produção e de subsistência. $O$ trabalho associado, dessa maneira, é "uma forma de atividade na qual os indivíduos põem as suas forças em comum e elas permanecem diretamente comuns do início ao fim do processo", por isso que esta sua natureza lhe possibilita ser a "matriz da forma mais aperfeiçoada possível da liberdade humana". Em suma, "o destino dos homens estará efetivamente em suas próprias mãos" e, em razão disto, que a "emancipação humana pode e deve ser posta como o fim mais alto da humanidade" (TONET, 2005, p. 155). É em decorrência disso que o proletariado deve se guiar pela luta para além do capital e não pelas limitações estruturais da emancipação política.

\section{Considerações Finais}

O presente artigo é uma defesa da necessidade de resgatar a perspectiva revolucionária e crítica inerente à teoria marxiana no que se refere à centralidade ontológica e política do trabalho e, ainda, com relação às distinções qualitativas entre a emancipação política e a emancipação humana. Não há dúvidas, tanto entre aqueles que se consideram na "esquerda", quanto nos expoentes mais conservadores da "direita", de que vivemos uma crise aguda e jamais vista. Mészáros caracterizou bem a "novidade histórica" do atual momento ao qualificar de "crise estrutural do capital" que atinge todas as esferas e dimensões da vida social. Neste aspecto, muitas posturas de cunho reformista e/ ou politicistas andam "de mãos dadas" com as próprias alienações que 
brotam do solo contraditório e desigual do sistema do capital e, neste círculo vicioso, dificultam uma compreensão profunda da realidade objetiva por meio de um conhecimento de orientação revolucionária.

É no bojo deste processo que muitos discursos e seus mais "brilhantes" interlocutores invertem a relação entre os complexos sociais, colocando na política a centralidade do processo de transição do capitalismo rumo ao socialismo. Ainda mais, abandonam o fato do proletariado ser o sujeito revolucionário e contribuem, desta forma, para o fortalecimento do avanço do capital sobre a consciência dos trabalhadores e, ao mesmo tempo, para que as deturpações do pensamento marxiano continuem a se reproduzir nos seus mais grotescos preconceitos. Reafirmamos e insistimos que o proletariado continua, tal como o era na época de Marx, a única classe produtora de todo 'conteúdo material da riqueza social e, portanto, continua "a única classe que não tem nada a perder, a não ser os seus grilhões, com o desaparecimento da exploração do homem pelo homem" (LESSA, 2007, p. 316).

É preciso entender que com a perda da especificidade ontológica do trabalho frente às outras práxis sociais não se perde apenas o fundamento ontológico da centralidade revolucionária do proletariado, mas também, se perde a "maior conquista do pensamento marxiano, qual seja: "ter demonstrado o porquê e o como de os homens serem os únicos demiurgos de seu destino" e, com isso, "perde-se, in limine, a pedra de toque de toda ontologia marxiana" (LESSA, 2007, p. 336). O proletariado na luta revolucionária, desta forma, precisa se guiar pela emancipação humana, pelo avanço do trabalho associado sobre o trabalho assalariado, superando - com base na concepção radical - a propriedade privada, o Estado, as classes sociais e toda forma de exploração do homem pelo homem. Só assim, então, o cidadão cederá lugar ao ser, ao pleno ser humano.

\section{Referências}

CHASIN, J. Democracia Política e Emancipação Humana. Revista Verinotio, n. 15, v. VIII, p. 22-27, 2012 a. 
CHASIN, J. Marx. A determinação ontonegativa da politicidade. Revista Verinotio, n. 15, v. VIII, p. 42-59, 2012 b.

LESSA, S. "Centralidade ontológica" do trabalho e "centralidade política" proletária. Lutas Sociais, v. 13-14, p. 106-121, 2005.

Trabalho e Proletariado no Capitalismo Contemporâneo.

São Paulo: Cortez, 2007.

LUKÁCS, G. Para uma ontologia do ser social - II. São Paulo: Boitempo, 2012.

TONET, I. Educação, Cidadania e Emancipação Humana. Ijuí: Unijuí, 2005.

TONET, I.; LESSA, S. Proletariado e sujeito revolucionário. São Paulo: Instituto Lukács, 2012. 